\title{
Expressão do afeto e bem-estar subjetivo em pessoas casadas
}

\author{
Fabio Scorsolini-Comin \\ Universidade Federal do Triângulo Mineiro \\ Manoel Antônio dos Santos \\ Universidade de São Paulo \\ Roberto Molina de Souza \\ Universidade Tecnológica Federal do Paraná
}

\begin{abstract}
Resumo
O objetivo deste estudo foi verificar as correlações existentes entre os domínios do bem-estar subjetivo (BES) e a expressão do afeto. A amostra foi composta por 106 pessoas casadas. Os instrumentos utilizados foram: Questionário Sociodemográfico, Escala Abipeme, Escala de Bem-estar Subjetivo e Escala de Ajustamento Diádico. Os resultados da análise multivariada evidenciaram que a expressão do afeto está correlacionada com afetos positivos e negativos, mas significativamente relacionada apenas à categoria de afetos positivos, a partir da seleção de variáveis pelo método stepwise ( $r h o=0,04 ; p=0,01$ ). Desse modo, quanto mais a pessoa se sente feliz, mais tende a expressar sua afetividade quando está com o parceiro. A partir das contribuições da Psicologia Positiva, podemos compreender que o modo como cada cônjuge se sente em termos individuais e se coloca em relação ao mundo e às diferentes experiências contribui para que se sinta seguro e possa expressar a afetividade de maneira mais satisfatória.
\end{abstract}

Palavras-chave: bem-estar subjetivo, afetividade, ajustamento diádico, relações conjugais, escalas.

\begin{abstract}
Expression of affection and well-being subjective in married people. This study aimed at analyzing and comparing the constructs of subjective well-being and the expression of affection, using a sample of 106 married people. The following instruments were used: Sociodemographic Questionnaire, Socioeconomic Questionnaire, Dyadic Adjustment Scale and Subjective Well-being Scale. The results showed that expression of affection is correlated with positive affect and negative affect, but only significantly related to the level of positive affect from the variable selection stepwise ( $r h o=0.04, p=0.01)$. Thus, the more one feels happy and willing to establish contacts with other, the more likely to also express their affection when you're with your partner. According to the Positive Psychology, the way each partner feels in individual terms and arises in relation to the world and different experiences helps them to feel safe and can express affection in a more satisfactory way.
\end{abstract}

Keywords: subjective well-being; affection; dyadic adjustment; marital relationships; scales.

$\mathrm{S}$ egundo a literatura científica, pessoas casadas de ambos os sexos relatam mais felicidade do que aquelas que nunca casaram ou são divorciadas, separadas ou viúvas. Pessoas que coabitam com um parceiro também são significativamente mais felizes em algumas culturas do que aquelas que vivem sozinhas (Diener \& Lucas, 2000; Lee, Seccombe, \& Shehan, 1991; Seligman, 2004, 2011). A relação entre bem-estar subjetivo - BES (considerado o estudo científico da felicidade) e ser casado se aplica a pessoas de todas as idades, níveis de renda, graus de instrução e origens racial-étnicas, sendo a qualidade da vida conjugal associada positivamente ao bem-estar pessoal (Snyder \& Lopez, 2009).

O casal contemporâneo é confrontado por duas forças paradoxais: individualidade e conjugalidade. $\mathrm{O}$ desafio reside, fundamentalmente, no fato de o casamento ou união ser um palco no qual devem se entrelaçar as individualidades de cada membro, operando-se a construção de um lugar em comum (Féres-Carneiro, 1998; Magalhães, 2009). Este lugar que cada par cria para lidar com as tensões produzidas pelo embate entre individualidade e conjugalidade é denominado "absoluto do casal". Este conceito configura a identidade conjugal, que na literatura especializada é reconhecida como conjugalidade (Caillé, 1991; Cicco, Paiva, \& Gomes, 2005; Féres-Carneiro, 1998).

A respeito da mensuração da conjugalidade, Spanier (1976) propôs a expressão "ajustamento conjugal" para referir-se à dimensão do ajustamento, comunicação, felicidade, integração e satisfação intradíade. A conceituação do que seria um casamento satisfatório é uma tarefa árdua e desafiadora para o conhecimento científico, uma vez que a análise das pesquisas internacionais 
da área, na última década, aponta para um alto índice de fatores que se associam à definição do conceito de satisfação conjugal (Mosmann, Wagner, \& Féres-Carneiro, 2006; Scorsolini-Comin \& Santos, 2009, 2011b).

Uma vertente que vem se consolidando na literatura é a busca de uma melhor delimitação do campo conceitual a partir de estudos fundamentados empiricamente. Nessa tradição, é valorizada a construção de instrumentos analíticos que permitam a mensuração das variáveis envolvidas. Um dos instrumentos mais utilizados é a Dyadic Adjustment Scale (DAS), desenvolvida por Spanier (1976) com base no conceito de ajustamento conjugal. De acordo com esse autor, o ajustamento conjugal pode ser concebido em duas perspectivas distintas: como um processo ou uma avaliação qualitativa de um estado. $\mathrm{Na}$ primeira perspectiva, do ajustamento como um processo, pressupõe-se uma análise em busca das transformações ao longo do tempo e em função de eventos críticos, tais como nascimento dos filhos, entrada dos filhos na escola, evolução na carreira profissional, aposentadoria, adoecimento, entre outros marcos de transição psicossocial. Para o autor, definir ajustamento conjugal como um processo tem diversas implicações, sendo a mais importante a de que um processo pode ser melhor investigado ao longo do tempo. $\mathrm{Na}$ segunda tendência, de compreender o ajustamento diádico como um estado, tem-se acesso ao sujeito em um dado momento de seu desenvolvimento, sendo a avaliação pontual, na medida em que retrata apenas o que está acontecendo em tal circunstância. Segundo Hernandez e Hutz (2008), os estudos transversais na investigação do ajustamento têm algum valor; contudo, é evidente que um processo pode ser melhor observado mediante delineamentos longitudinais. Daí decorre a recomendação de que as pesquisas sobre conjugalidade sejam conduzidas por meio de desenhos longitudinais. Contudo, as dificuldades de viabilizar estudos com esse tipo de delineamento justificam o predomínio de cortes transversais na investigação do ajustamento diádico (Scorsolini-Comin \& Santos, 2010b).

Ainda segundo esses autores, a DAS teve sua primeira análise fatorial confirmatória realizada em 1982, na qual foi encontrada uma solução para quatro fatores, que explicaria $94 \%$ da covariância entre os itens. O coeficiente alfa de Cronbach para a escala total foi de 0,91 . A escala é constituída pelas dimensões: (a) Consenso diádico, que avalia a percepção do nível de concordância do casal acerca de uma variedade de questões básicas da relação conjugal, a saber: financeiras, religiosas, de lazer, amizades, convencionalidade, filosofia de vida, entre outras; (b) Satisfação diádica, que mede a percepção das questões relativas à discussão do divórcio, à saída de casa após briga, ao arrependimento com o casamento, à implicância mútua, ao estar bem, à confiança no cônjuge, entre outras (Hernandez \& Hutz, 2008); (c) Coesão diádica, que examina o senso de compartilhamento emocional do casal; (d) Expressão diádica de afeto, que mede a percepção da concordância dos cônjuges sobre as demonstrações de afeto, as relações sexuais, a falta de amor e as recusas ao sexo (Hernandez, 2008; Hernandez \& Hutz, 2008). Considerando-se o conhecimento disponível na literatura, observa-se um predomínio de estudos que consideram a satisfação diádica como dimensão central do ajustamento diádico (Scorsolini-Comin, 2009). No estudo original da DAS, os índices de consistência interna (alfa de Cronbach) encontrados foram: 0,90 (consenso diádico), 0,94 (satisfação diádica), 0,86 (coesão diádica) e 0,73 (expressão do afeto) (Spanier, 1976). Por compreendermos que a expressão da afetividade é uma das principais dimensões que caracterizam um relacionamento amoroso em termos da conjugalidade, este domínio foi eleito como foco da presente investigação.

\section{Bem-estar subjetivo: o estudo cientifico da felicidade}

Apesar do reconhecimento de grande parte das ciências humanas de que a felicidade é a meta fundamental da vida, ainda há pouco progresso com relação ao entendimento do que, de fato, consiste a felicidade. As pesquisas têm corroborado que aspectos como segurança material, luxo e dinheiro não são, por si só, garantia de felicidade, bem-estar e qualidade de vida (Csikzentmihalyi \& Csikzentmihalyi, 2006; Seligman, 2011). O BES tem sido considerado como o estudo científico da felicidade; trata-se de uma experiência interna de cada indivíduo, que emite um julgamento de como ele se sente e seu grau de satisfação com a vida (Albuquerque, 2004; Seligman, 2004; Snyder \& Lopez, 2009; Stones, Worobetz, \& Brink, 2011).

Apesar das discordâncias teóricas relativas à conceituação de BES, existe um consenso quanto às suas dimensões: satisfação com a vida e afetos positivos e negativos (Anguas, 1997). Afeto positivo é um contentamento hedônico puro experimentado em um determinado momento como um estado de alerta, de entusiasmo e de atividade. É um sentimento transitório de prazer ativo. Trata-se mais de uma descrição de um estado emocional do que um julgamento cognitivo. Afeto negativo refere-se a um estado de distração e engajamento desprazível que também é transitório, mas que inclui emoções desagradáveis como ansiedade, depressão, agitação, aborrecimento, pessimismo e outros sintomas psicológicos aflitivos e angustiantes. A dimensão satisfação com a vida é um julgamento cognitivo de algum domínio específico na vida da pessoa; um processo de juízo e avaliação geral da própria vida; uma avaliação sobre a vida de acordo com um critério próprio (Diener, Suh, \& Oishi, 1998).

Em relação aos fatores que influenciam o BES, convém lembrar que este construto sofre influência tanto cultural (experiências compartilhadas que formam a base de uma maneira similar de ver o mundo) como da hereditariedade (Albuquerque \& Tróccoli, 2004; Lykken \& Tellegen, 1996). O sentido das experiências dos indivíduos é construído socialmente por meio de crenças, pressuposições e expectativas sobre o mundo ligadas também à transmissão que ocorre no âmbito da família. Em um estudo com 10\% dos estudantes mais felizes dos Estados Unidos (Diener \& Lucas, 2000; Snyder \& Lopez, 2009), concluiu-se que as qualidades de boa saúde mental e bons relacionamentos sociais surgiam constantemente na vida desses jovens adultos, o que evidencia a importância de um bom funcionamento social. A partir de estudos como esses, que destacam as características positivas dos indivíduos e sua repercussão para a saúde e o bem-estar, é que se coloca a perspectiva da Psicologia Positiva.

\section{Marco teórico: psicologia positiva}

A Psicologia Positiva ocupa-se do estudo científico das forças e virtudes próprias do indivíduo. Trata-se da investigação 
de sentimentos, práticas e emoções que contribuem para o bem-estar (Seligman, 2011). A ciência e a prática da Psicologia Positiva estão voltadas para a identificação e compreensão das qualidades e virtudes humanas, bem como para a promoção da saúde no sentido de que as pessoas tenham vidas mais felizes e produtivas (Snyder \& Lopez, 2009).

A Psicologia Positiva se sustenta sobre três pilares principais, a saber: o estudo da emoção positiva; o estudo dos traços ou qualidades positivas, principalmente forças e virtudes, incluindo habilidades como inteligência e capacidade atlética; e, por fim, o estudo das chamadas instituições positivas, como a democracia, família e liberdade, que dão suporte às virtudes que, por sua vez, apoiam as emoções positivas (Seligman, 2004, 2011). A Psicologia Positiva pretende considerar as experiências positivas, como emoções positivas, felicidade, esperança, alegria, características positivas individuais, caráter, força, coragem, virtude e instituições positivas (Lawrence \& Liang, 1988; Scorsolini-Comin, 2009; Scorsolini-Comin \& Santos, 2009, 2010a, 2011a, 2011b; Seligman, 2004; Snyder \& Lopez, 2009).

Feitas essas considerações, o objetivo deste estudo foi verificar as correlações existentes entre os fatores do bem-estar subjetivo (BES) e o fator do ajustamento diádico intitulado expressão do afeto, em pessoas casadas.

A hipótese a ser testada é a de que a expressão do afeto está positiva e significativamente correlacionada com os afetos positivos e à satisfação com a vida.

\section{Método}

\section{Tipo de estudo}

Trata-se de um estudo descritivo, transversal e correlacional, com enfoque quantitativo e tratamento estatístico dos dados.

\section{Participantes}

Em relação aos critérios de inclusão/exclusão dos participantes, não se restringiu duração máxima para os casamentos, idade, ocupação, quantidade de filhos ou classificação socioeconômica. Foram definidos como critérios de inclusão: estar consensualmente casado há, no mínimo, um ano; não apresentar indícios aparentes de comprometimento cognitivo ou comportamental, que poderiam afetar a resposta aos instrumentos utilizados (como quadros de demência ou transtornos mentais, inferidos por antecedentes de internação psiquiátrica ou pelo fato de estar em tratamento psiquiátrico ou fazer uso crônico de psicotrópicos); não estar em processo de separação conjugal.

Em termos do perfil sociodemográfico, a amostra foi composta por 106 participantes (membros de 53 casais heterossexuais), legalmente casados há, no mínimo, um ano, com ou sem filhos. Neste estudo, não foram estudadas as correlações intradíades (grau de consenso entre os membros do par), mas sim as respostas dessas pessoas casadas, de modo independente. A média em anos de casamento foi de 16,11 $\pm 11,35$. No que concerne à faixa etária dos participantes, a idade média foi de $42 \pm 11$ anos. A média de idade dos homens foi de 43,4 anos, ao passo que a das mulheres foi de 40,7. Em relação ao número de filhos dos casais participantes, a média foi de 1,49 filhos para cada participante, com desvio padrão de 1,22 . No que concerne à classificação socioeconômica, a partir do critério Abipeme (1997), a maioria dos participantes pertencia à classe $\mathrm{B}(60,37 \%)$. Atrelada à classificação do status socioeconômico, a renda per capita foi de 5,03 salários, com desvio-padrão de 3,63. Em relação ao grau de instrução dos participantes, a maioria (66,98\%) possuía nível superior, o que se observou tanto entre homens quanto entre mulheres.

\section{Coleta dos dados}

Os participantes foram selecionados pela técnica da "bola de neve", em que novos participantes foram indicados pelos próprios respondentes, a partir dos contatos do pesquisador. Após serem esclarecidos sobre a pesquisa, os participantes assinaram o Termo de Consentimento Livre e Esclarecido e preencheram os questionários e escalas. A aplicação da bateria de instrumentos foi realizada individualmente com cada participante, ou seja, mesmo se tratando de casais, cada membro respondeu de modo independente (sem a presença do cônjuge). Outro cuidado para assegurar a aplicação independente foi de que os respondentes não tivessem acesso às respostas do parceiro (acesso aos instrumentos respondidos, nem conversa após a aplicação, por exemplo), o que poderia influenciar nas respostas. Assim, a aplicação com cada cônjuge foi feita de modo sequenciado e independente.

Este estudo foi aprovado pelo Comitê de Ética em Pesquisa da Faculdade de Filosofia, Ciências e Letras de Ribeirão Preto, Universidade de São Paulo (Processo no 349/2007).

\section{Instrumentos}

Questionário sociodemográfico. desenvolvido pelos autores deste estudo para identificação geral do participante e sua inserção social, econômica e demográfica. Foram incluídas perguntas como idade, grau de escolaridade, renda familiar e religião.

Escala Abipeme de classificação socioeconômica. O critério Abipeme (1997) é uma escala ou classificação socioeconômica aferida por intermédio da atribuição de pesos a um conjunto de itens de conforto doméstico, além do nível de escolaridade do chefe de família. A classificação socioeconômica da população é apresentada por meio de cinco classes, denominadas A, B, C, $\mathrm{D}$ e E, que correspondem, respectivamente, a uma pontuação determinada.

Escala de bem-estar subjetivo - EBES (Albuquerque \& Tróccoli, 2004). Trata-se de um instrumento inspirado em escalas elaboradas originalmente no contexto internacional: Escala de Afeto Positivo e Afeto Negativo - PANAS (Watson, Clark, \& Tellegen, 1988), Escala de Satisfação com a Vida SWLS (Diener, Emmons, Larsen, \& Griffin, 1985) e Escala de Bem-estar Subjetivo - SWBS (Lawrence \& Liang, 1988), com itens elaborados e analisados em grupos de validação semântica. O instrumento é composto por duas subescalas de resposta tipo Likert de cinco pontos. Na primeira parte da escala, os itens vão do número 1 ao 47 e descrevem afetos positivos $(\alpha=0,95)$ 
e negativos $(\alpha=0,95)$. Na segunda parte da escala, os itens vão do número 48 ao 62 e descrevem julgamentos relativos à avaliação de satisfação ou insatisfação com a vida $(\alpha=0,90)$. A EBES é uma das escalas mais utilizadas em estudos que adotam o referencial da Psicologia Positiva, uma vez que seus itens foram construídos a partir de pressupostos dessa abordagem (Scorsolini-Comin \& Santos, 2011b).

Escala de ajustamento diádico - DAS (Spanier, 1976). Instrumento de origem norte-americana que avalia a percepção de casais acerca de seus relacionamentos afetivos. É uma escala mundialmente conhecida, com adaptações para vários países e culturas. No Brasil, foi traduzida e validada por Hernandez (2008). Embora não tenha sido construída a partir do referencial da Psicologia Positiva, trata-se de um instrumento que avalia o ajustamento do casal a um ideal de relacionamento, considerado importante na avaliação dos relacionamentos avaliados como positivos (Seligman, 2011).

\section{Análise dos dados}

Os dados obtidos com a aplicação dos instrumentos foram transpostos para o Software SAS 9.2 (2003) e categorizados a partir de números de identificação, por casal, por sexo e, consequentemente, por participante. Embora a coleta tenha sido realizada com casais, a análise foi conduzida individualmente (por participantes), sem considerar as díades (casais). Foram calculadas as correlações entre as variáveis contínuas dos seguintes domínios: a) consenso; b) satisfação diádica; c) coesão; d) expressão do afeto (a, b, c, d são domínios de ajustamento diádico, pela DAS); e) afetos positivos; f) afetos negativos; e g) satisfação com a vida (e, f, g são domínios de bem-estar subjetivo, segundo a EBES). Especificamente neste estudo, serão analisadas em profundidade as correlações entre os domínios identificados pelas letras d, e, f, g. A força da grandeza do coeficiente de correlação foi avaliada conforme procedimento proposto pela literatura (Zou, Tuncali, \& Silverman, 2003). O nível de significância adotado foi de $p \leq 0,05$.

Depois da definição das correlações, estabeleceu-se a relação dos escores totais dos diversos domínios a partir de um modelo linear múltiplo em que todas as variáveis foram consideradas a princípio. Para estabelecer o modelo final, todas as variáveis ( $\mathrm{a}, \mathrm{b}, \mathrm{c}, \mathrm{d}, \mathrm{e}, \mathrm{f}, \mathrm{g})$ foram submetidas ao método de seleção de variáveis stepwise, no qual permaneceram no modelo aquelas que apresentaram maior evidência de significância do ponto de vista multivariado. A adoção desse método permitiu filtrar, dentre todas as variáveis elencadas, as que tinham maior poder de predição, uma vez que se trata de uma ferramenta de análise adequada para examinar e entender os diversos tipos de relacionamentos interdependentes (Hair, Anderson, Tatham, \& Black, 1995; Montgomery, Vining, \& Peck, 2001; Siegel \& Castellan, 1998).

\section{Resultados}

A partir dos escores obtidos, serão apresentadas as correlações, enfatizando-se as mais significativas. As tabelas 1 e 2 resumem as correlações entre os construtos elencados e a análise de regressão múltipla pelo método de seleção de variáveis stepwise, respectivamente.

Analisando-se a satisfação com a vida (variável do construto BES) e a satisfação diádica (variável de ajustamento diádico), observou-se que as mesmas estão positiva e significativamente

Tabela 1

Matriz de correlações entre os domínios dos construtos bem-estar subjetivo e ajustamento diádico e valores de $p$ $(N=106)$. Em negrito, as correlações mais robustas.

\begin{tabular}{ccccc}
\hline & Afetos positivos & Afetos negativos & $\begin{array}{c}\text { Satisfação com a } \\
\text { vida }\end{array}$ & Expressão do afeto \\
\hline Afetos positivos & - & $\mathbf{- 0 , 4 5}$ & $\mathbf{0 , 1 9}$ & $\mathbf{0 , 4 5}$ \\
& & $\mathbf{( < 0 , 0 1 )}$ & $\mathbf{( 0 , 0 5 )}$ & $\mathbf{( < 0 , 0 1 )}$ \\
Afetos negativos & - & - & 0,09 & $\mathbf{- 0 , 2 5}$ \\
Satisfação com a vida & - & - & $(0,35)$ & $\mathbf{( 0 , 0 1 )}$ \\
& & & $-0,06$ & $(0,57)$ \\
\hline
\end{tabular}

correlacionadas ( $r h o=0,20 ; p=0,04)$, o que revela que pessoas que se dizem satisfeitas com a vida em diferentes domínios também o fazem em relação à experiência conjugal.

Ainda por essa análise, a satisfação com a vida também seria influenciada diretamente pelos afetos positivos e negativos, corroborando a consistência interna do construto. Ou seja, para que uma pessoa faça uma avaliação de sua vida e um julgamento pessoal em termos de satisfação com as diversas dimensões que o compõem, precisa ter bom nível de afetos positivos e baixo nível de afetos negativos. Por outro lado, a satisfação com a vida mostra-se correlacionada com a variável idade.

A satisfação com a vida não apresentou correlação com o consenso diádico ( $r h o=0,01 ; p=0,92$ ). Esse resultado não seguiu a tendência das demais variáveis de BES (afetos positivos e afetos negativos), todas correlacionadas moderadamente com o consenso diádico. Não encontramos aporte na literatura para explicar tal achado, embora possamos hipotetizar que o nível de concordância do casal não interferiria de modo decisivo na percepção de satisfação com a vida, ao contrário de outras variáveis, como o nível de satisfação com a própria relação, que é considerada um importante aspecto dos relacionamentos positivos, segundo a Psicologia Positiva (Seligman, 2011). Pela análise de regressão múltipla stepwise, a satisfação com a vida mostrou-se significativamente correlacionada com os demais domínios do BES (afetos positivos, $r h o=0,11, p=0,01$; afetos negativos, rho $=0,06, p=0,01)$ e com o domínio satisfação diádica. Há que se destacar que o método stepwise "filtra", dentre todas as variáveis, as que apresentam maior poder de 
Tabela 2

Resultados do modelo de regressão ajustado utilizando o método de seleção de variáveis stepwise $(N=106)$. A estimativa do parâmetro foi definida por meio do método de mínimos quadrados (Least Mean Square Method). Em negrito, as correlações mais robustas.

\begin{tabular}{|c|c|c|c|}
\hline $\begin{array}{l}\text { Variável } \\
\text { Resposta } \\
\end{array}$ & $\begin{array}{c}\text { Variáveis } \\
\text { Explicativas }\end{array}$ & $\begin{array}{c}\text { Estimativa } \\
\text { do Parâmetro }\end{array}$ & $p$ \\
\hline Afetos positivos & $\begin{array}{c}\text { Afetos negativos } \\
\text { Expressão do afeto } \\
\text { Idade } \\
\end{array}$ & $\begin{array}{r}-\mathbf{0 , 3 5} \\
\mathbf{1 , 8 3} \\
-0,14 \\
\end{array}$ & $\begin{array}{l}\mathbf{0 , 0 1} \\
\mathbf{0 , 0 1} \\
0,11 \\
\end{array}$ \\
\hline Afetos negativos & Afetos positivos & $-0,55$ & $\mathbf{0 , 0 1}$ \\
\hline Satisfação com a vida & $\begin{array}{l}\text { Afetos positivos } \\
\text { Afetos negativos } \\
\text { Idade }\end{array}$ & $\begin{array}{l}\mathbf{0 , 1 1} \\
\mathbf{0 , 0 6} \\
\mathbf{0 , 0 6}\end{array}$ & $\begin{array}{l}0,01 \\
0,01 \\
0,05\end{array}$ \\
\hline Expressão do afeto & $\begin{array}{c}\text { Afetos positivos } \\
\text { Renda }\end{array}$ & $\begin{array}{r}\mathbf{0 , 0 4} \\
-0,06\end{array}$ & $\begin{array}{l}\mathbf{0 , 0 1} \\
0,09\end{array}$ \\
\hline
\end{tabular}

predição de um dado fator. Desse modo, os afetos positivos, os afetos negativos e a satisfação diádica possuem maior poder de predizer o fenômeno da satisfação com a vida do que os demais fatores estudados.

Correlacionando-se os domínios de conjugalidade (consenso, coesão, satisfação e expressão do afeto) entre si, observa-se que todos estão correlacionados $(p<0,01)$, corroborando os estudos que remontam à elaboração da Escala de Ajustamento Diádico (Spanier, 1976). No entanto, pela análise de regressão múltipla, quando se analisa cada uma das variáveis de conjugalidade em relação às demais do mesmo domínio, observa-se que não há uma correlação significativa, a exceção do consenso, diretamente relacionado à coesão diádica.

Os resultados mostraram que o consenso está correlacionado com a satisfação ( $r h o=-0,25 ; p<0,01)$, com a coesão $(r h o=$ $0,55 ; p<0,01)$ e a expressão do afeto ( $r h o=0,45 ; p<0,01)$. A partir da análise de regressão múltipla, constatou-se que o consenso está diretamente relacionado apenas com a coesão diádica e os afetos negativos. Desse modo, em termos das variáveis de conjugalidade, apresentam relação significativa o consenso e a coesão, o que permite problematizar que, quanto maior o consenso (concordância, flexibilidade) entre os cônjuges, mais eles tendem a se manter coesos, unidos, podendo adotar posturas semelhantes em relação ao casamento.

A variável de ajustamento diádico denominada satisfação diádica está negativamente correlacionada apenas ao domínio de consenso. Não pode ser associada aos domínios de coesão (rho $=-0,13 ; p=0,18)$ e expressão do afeto $(r h o=-0,14 ; p=0,16)$, o que caminha em sentido oposto ao destacado por Spanier (1976), de que esses domínios são correlacionados significativamente. Pela análise de regressão múltipla, a satisfação diádica não sofre influências de quaisquer das dimensões da conjugalidade mensuradas pelo DAS.

O domínio do ajustamento diádico denominado coesão se refere à proximidade e ao sentimento de conexão e intimidade percebidos pelo casal, com um compromisso partilhado com a relação e com sua continuidade, um sentimento de preservação da relação e do vínculo, de forma a diminuir as influências de outros sobre a relação. No presente estudo, a coesão encontra-se positivamente correlacionada com a expressão do afeto, também um domínio da conjugalidade ( $r h o=0,47 ; p<0,01$ ). Essa correlação é considerada moderada (Zou, Tuncali, \& Silverman, 2003). A coesão também pode ser negativamente correlacionada com os domínios da satisfação conjugal: aspectos emocionais (rho $=-0,31 ; p<0,01)$, aspectos estruturais (rho $=-0,48 ; p<$ $0,01)$ e interação conjugal (rho $=-0,55 ; p<0,01)$.

A expressão do afeto (Spanier, 1976) é definida como a percepção subjetiva acerca da concordância ou discordância de um casal em questões relativas à forma e frequência de demonstrações de carinho, afeto e desejo sexual. Na DAS, a expressão do afeto é aferida por meio do grau de concordância ou discordância em relação às demonstrações de afeto e relações sexuais e, em relação às duas últimas semanas, se o casal apresentou problemas em relação a estar cansado demais para sexo e não demonstração do amor (Perlin, 2006). Em relação à expressão do afeto (domínio da conjugalidade), esta seria direta e significativamente influenciada apenas pelos afetos positivos $(r h o=0,45 ; p<0,01)$ e negativos $(r h o=-0,25 ; p<$ 0,01) (Tabela 1).

Assim, quanto maior o nível de afetos positivos, maior a tendência ao indivíduo expressar sua afetividade em seus relacionamentos. De modo oposto, quanto maior o nível dos afetos negativos, menor a tendência de o indivíduo expressar seus afetos. Isso é corroborado pelo fato de que os afetos negativos são voltados fundamentalmente à própria pessoa, como no caso do sentimento de depressão e desilusão. São sentimentos direcionados ao próprio indivíduo, em uma tendência introversiva. Quanto mais a pessoa se sente feliz, alegre, expansiva e com disposição para estabelecer contatos com os outros, mais tende a expressar também sua afetividade quando está com o parceiro.

Pela análise stepwise, no entanto, apenas os afetos positivos estão diretamente correlacionados com a expressão do afeto ( $r$ o $=0,04 ; p=0,01)$, o que significa que tais afetos positivos são mais determinantes (ou preditores) do alto nível de expressão do afeto em um relacionamento conjugal do que os afetos negativos. Ainda de acordo com a análise stepwise, a expressão do afeto estaria direta e significativamente correlacionada com a renda per capita, ou seja, quanto maior a expressão do afeto, maior a renda per capita. No entanto, não encontramos aporte científico 
na literatura consultada para explicar tal achado.

\section{Discussão}

A correlação positiva entre satisfação com a vida e a satisfação diádica confirmou a hipótese deste estudo, na medida em que ambos os fatores, por avaliarem o julgamento da pessoa sobre o que vivencia (em sua vida de casada ou não) em relação aos seus desejos e expectativas construídas cultural e socialmente, manteriam uma relação de semelhança na definição dos construtos. A satisfação com a vida, por envolver um julgamento global acerca do bem-estar, também abarca os relacionamentos afetivos. Assim, a satisfação conjugal, na amostra investigada, está positiva e significativamente correlacionada com a satisfação com a própria vida. Esse apontamento é corroborado também pela análise de regressão múltipla tipo stepwise, que verifica quais variáveis estão mais diretamente relacionadas a um dado fenômeno. A Psicologia Positiva, como ciência que investiga o bem-estar, considera que o conceito de satisfação é um importante demarcador no sentido de identificar os aspectos positivos e adaptativos do ser humano. Além disso, mostra que a satisfação com a vida, como um fator que perpassa os vários domínios da vida, abarca a conjugalidade como um aspecto que sempre deve ser considerado ao se investigar o bem-estar, ou seja, deve-se incluir a afetividade como parte das experiências prazerosas do indivíduo.

Uma boa avaliação da satisfação no relacionamento diádico deve vir acompanhada de bom nível de afetos positivos, baixo nível de afetos negativos e de um similar grau de satisfação com a vida. Pode-se problematizar no sentido de que ambas as satisfações (do BES e do ajustamento conjugal) apontam para uma mesma direção, ou seja, avaliar o casamento passaria, inequivocamente, não apenas por uma avaliação da própria vida, mas por uma reflexão acerca do papel desempenhado pelo relacionamento afetivo na constituição da pessoa e da vivência da conjugalidade.

Segundo a literatura, notadamente da Psicologia Positiva, a percepção satisfatória acerca do casamento está diretamente relacionada a uma avaliação satisfatória da vida de cada cônjuge e também a um baixo nível de afetos negativos (Lee, Seccombe, \& Shehan, 1991; Snyder \& Lopez, 2009). Ou seja, o casamento, avaliado na perspectiva desses domínios, está correlacionado a aspectos individuais trazidos e percebidos por cada cônjuge. Assim, o espaço conjugal atualizaria os aspectos trazidos por cada parceiro, configurando um locus de compartilhamento não apenas de experiências, desejos e sentimentos, mas também de percepções mais ou menos satisfatórias acerca da vida e de suas dimensões, como projetos comuns (Perlin, 2006). Isso reforça a relevância da investigação acerca do modo como cada cônjuge se coloca na relação, transferindo suas percepções e posicionamentos não apenas em termos de expectativas acerca do relacionamento conjugal, mas em termos de suas expectativas individuais em relação ao que é ser feliz e como se pode buscar a satisfação, o que permite destacar o casamento como uma possibilidade de realização dessa expectativa. Há que se considerar, ainda, que Seligman (2011), considerado o criador da Psicologia Positiva, destaca que um dos pilares dessa ciência estaria no estabelecimento de relacionamentos considerados positivos. O casamento ou a experiência conjugal seria, portanto, um importante elemento a ser considerado ao avaliar a qualidade dos relacionamentos estabelecidos pelo indivíduo.

Considerando os resultados da análise de regressão múltipla, deve-se ponderar que o consenso está significativamente relacionado à coesão, mas o contrário não se mostrou verdadeiro. Assim, casais coesos tendem a ter maior nível de consenso, mas casais que experimentam grande consenso nem sempre são coesos. Pode-se depreender dessa relação que manifestar bom grau de concordância em relação aos diversos aspectos do casamento não implica, necessariamente, na união (coesão) entre os parceiros e tampouco no alcance da felicidade.

Dessa maneira, pode-se afirmar que, na amostra investigada, quanto maior a insatisfação do casal em relação ao casamento e/ ou ao cônjuge, menor a expressão de afeto positivo vivenciado na relação conjugal. Pode-se compreender que, em relacionamentos cujos cônjuges estejam insatisfeitos, diminuiria a frequência de demonstrações de amor e carinho, bem como as atividades sexuais (Gottman, 1998). Como já destacado, a DAS não cobre todo o processo de construção e desenvolvimento da conjugalidade do casal, mas a expressão do afeto em um determinado ponto da relação, o que justifica a delimitação do tempo em relação a esses aspectos (duas últimas semanas). Sendo assim, nossos resultados devem ser considerados, tendose em mente essa delimitação temporal na caracterização do domínio expressão do afeto. Ainda que seja uma delimitação datada, podemos considerar o ajustamento diádico como um padrão que pode ser repetido ao longo do tempo, reforçando a consideração de que uma expressão positiva do afeto possa também contribuir para o estabelecimento de relacionamentos positivos, um dos aspectos mais significativos do conceito de bem-estar na perspectiva da Psicologia Positiva.

\section{Conclusões}

Considerando os domínios específicos de cada construto, encontrou-se uma correlação moderada e significativa entre a satisfação com a vida (fator do BES) e a satisfação diádica (fator do ajustamento diádico). Esse achado permite afirmar que, na avaliação de bem-estar, o relacionamento afetivo ocupa um lugar de destaque, uma vez que é uma fonte significativa de prazer. Retomando uma das problematizações iniciais que motivaram este estudo, pode-se destacar que o ajustamento diádico (notadamente, a satisfação diádica) teria um papel importante na avaliação subjetiva de bem-estar, uma vez que este domínio interfere no modo como cada cônjuge não apenas percebe seu casamento, mas também como o avalia, tendo como referência os demais relacionamentos presentes em seu meio social e cultural, bem como os seus próprios relacionamentos estabelecidos anteriormente. Deve-se destacar, nesse sentido, que os dados refletem um segmento específico da sociedade, constituído de indivíduos casados, de setores urbanos e classe média.

Pela análise dos dados, podemos afirmar que alguns fatores específicos do BES estão associados a certos fatores do ajustamento diádico. Desse modo, os afetos positivos mantêm uma correlação significativa com a coesão e a 
expressão do afeto, os afetos negativos estão negativamente relacionados ao consenso e satisfação diádicos e a satisfação com a vida está fortemente correlacionada com a satisfação diádica. Considerando a satisfação diádica, a expressão do afeto e o consenso como elementos que contribuiriam para o estabelecimento de relacionamentos positivos, pode-se afirmar, a partir do vértice da Psicologia Positiva, que o ajustamento diádico é um dos aspectos mais importantes do bem-estar. Essa afirmação é consistente com os apontamentos de Seligman (2011) acerca da relevância do casamento em relação ao estado de bem-estar.

Assim, o que cada cônjuge transfere para a relação deve ser apreendido como sua contribuição para a construção do espaço conjugal, ou seja, inevitavelmente, seus afetos positivos, afetos negativos e a forma como julga a sua vida fazem parte do seu modo de ser conjugal, isto é, do modo como ele se abre ao relacionamento e se desenvolve em seu casamento. Essa ponderação conduz, assim, para a consideração do BES na avaliação do casamento.

Avaliar a conjugalidade passa, inevitavelmente, por uma avaliação da própria satisfação em relação ao casamento e do modo como a afetividade vem sendo expressa. Mais do que isso, avaliar a percepção que os cônjuges possuem de seus relacionamentos pressupõe a consideração da complexidade de apreender todas as nuanças que envolvem o fenômeno, tais como o difícil delineamento dos domínios e dos próprios construtos teóricos.

O nível de satisfação pode ser um modulador das emoções, aumentando ou mitigando as positivas ou negativas, dependendo do que o indivíduo pensa, o que pode ser estendido à instituição casamento (Diener et al., 1998). O modo como cada cônjuge participa do estar junto em uma relação, compartilhando sentimentos, desapontamentos, diferenças e proximidades, pode ser um fator de satisfação não apenas com o domínio conjugal, como também com a própria vida.

Em termos da expressão do afeto, esta não é significativamente afetada pelos afetos negativos, nem pela satisfação com a vida, embora os afetos negativos estejam negativamente correlacionados com a expressão do afeto. Em termos de variáveis que diretamente causam modificações em outras, a expressão do afeto só está significativamente correlacionada com os afetos positivos, na medida em que ambas as dimensões destacam um afeto voltado para o exterior, ou seja, de tendência extroversiva, ainda que essas variáveis tenham um suporte no mundo interno de cada cônjuge. Dentro das limitações deste estudo, não se pôde corroborar a literatura que aponta que pessoas casadas são mais felizes do que as demais, mas se pode colocar em relevo, nos participantes casados, o papel desempenhado pela vivência e expressão da dinâmica conjugal na mensuração do próprio bem-estar subjetivo.

A partir do referencial da Psicologia Positiva, podemos compreender que o modo como cada cônjuge se sente em termos individuais e se coloca em relação ao mundo e às diferentes experiências contribui para que se sintam seguros e possam expressar a afetividade de maneira mais afirmativa, mais adaptativa e com maior possibilidade de caracterizar um relacionamento amoroso satisfatório. A construção de um relacionamento que possibilite a adequada expressão dos afetos pode ser determinante para que os cônjuges expressem não apenas suas emoções, mas que também comuniquem seus estados mentais, percepções e comportamentos. Um casamento que dê abertura para que os cônjuges se expressem e vivenciem sua afetividade de maneira positiva tenderá a promover maior identificação entre os cônjuges e maior possibilidade de que ambos experimentem uma conjugalidade capaz de promover bem-estar na díade.

\section{Referências}

Albuquerque, A. S. (2004). Bem-estar subjetivo e sua relação com personalidade, coping, suporte social, satisfação conjugal e satisfação no trabalho. (Tese de Doutorado não publicada). Universidade de Brasília, Brasília.

Albuquerque, A. S., \& Tróccoli, B. T. (2004). Desenvolvimento de uma escala de bem-estar subjetivo. Psicologia: Teoria e Pesquisa, 20(2), 153-164.

Anguas, A. (1997). El significado del bienestar subjetivo, su valoración en México. (Tese de Doutorado não publicada). Universidad Nacional Autónoma de México, Ciudad de México.

Associação Brasileira dos Institutos de Pesquisa de Mercado - Abipeme (1997). Critério de classificação socioeconômica - Brasil (CCSEB)

Caillé, P. (1991). Un et un font trois: Le couple révélé à lui-même. Paris: ESF.

Cicco, M. F., Paiva, M. L., \& Gomes, I. C. (2005). Família e conjugalidade: o sintoma dos filhos frente à imaturidade do casal parental. Psicologia Clínica, $17(2), 53-63$

Csikzentmihalyi, M., \& Csikzentmihalyi, I. S. (2006). A life worth living: contributions to Positive Psychology. Nova Iorque: Oxford University Press.

Diener, E., Emmons, R. A., Larsen, R. J., \& Griffin, S. (1985). The satisfaction with life scale. Journal of Personality Assessment, 49, 71-75.

Diener, E., \& Lucas, R. E. (2000). Explaining differences in societal levels of happiness: relative standards, need fulfillment, culture and evaluation theory. Journal of Happiness Studies, 1, 41-78.

Diener, E., Suh, E., \& Oishi, S. (1998). Recent findings on subjective well-being. Indian Journal of Clinical Psychology, 2, 25-41.

Féres-Carneiro, T. (1998). Casamento contemporâneo: o difícil convívio da individualidade com a conjugalidade. Psicologia: Reflexão e Crítica, 11(2), 379-394.

Gottman, J. (1998). Casamento: por que alguns dão certo e outros não? São Paulo: Objetiva.

Hair, J. F. J., Anderson, R. E., Tatham, R. L., \& Black, W. C. (1995). Multivariate data analysis with readings. $4^{\text {th }}$ ed. Nova Jersey: Prentice Hall.

Hernandez, J. A. E. (2008). Avaliação estrutural da escala de ajustamento diádico. Psicologia em Estudo, 13(3), 593-601.

Hernandez, J. A. E., \& Hutz, C. S. (2008). Gravidez do primeiro filho: papéis sexuais, ajustamento conjugal e emocional. Psicologia: Teoria e Pesquisa, 24(2), 133-141.

Lawrence, R. H., \& Liang, J. (1988). Structural integration of the affect balance scale and the life satisfaction index A: race, sex, and age differences. Psychology and Aging, 3, 375-384.

Lee, G. R., Seccombe, K., \& Shehan, C. L. (1991). Marital status and personal happiness: an analysis of trend data. Journal of Marriage and Family, 53, 839-844.

Lykken, D., \& Tellegen, A. (1996). Happiness is a stochastic phenomenon. Psychological Science, 7, 186-189.

Magalhães, A. S. (2009). Conjugalidade e parentalidade na clínica com famílias. In T. Féres-Carneiro (Org.), Casal e família: Permanências e rupturas (pp. 205-217). São Paulo: Casa do Psicólogo.

Montgomery, D., Vining, G., \& Peck, E. A. (2001). Introduction to linear regression analysis. John Wiley Profession.

Mosmann, C., Wagner, A., \& Féres-Carneiro, T. (2006). Qualidade conjugal: 
mapeando conceitos. Paideia (Ribeirão Preto), 16(35), 315-325.

Perlin, G. D. B. (2006). Casamentos contemporâneos: um estudo sobre os impactos da interação familia-trabalho na satisfação conjugal. (Tese de Doutorado não publicada). Universidade de Brasília, Brasília.

SAS/STAT/ $/{ }^{(2003) . ~ U s e r ' s ~ g u i d e: ~ V e r s i o n ~ 9.2 . ~ C a r y, ~ N C, ~ U S A: ~ S A S ~ I n s t i t u t e ~}$ Inc.

Scorsolini-Comin, F. (2009). Casar, verbo (in)transitivo: Conjugalidade, bemestar subjetivo e satisfação conjugal na perspectiva da Psicologia Positiva. (Dissertação de Mestrado não-publicada). Universidade de São Paulo, Ribeirão Preto.

Scorsolini-Comin, F., \& Santos, M. A. (2009). Casar e ser feliz: mapeando a mensuração da satisfação conjugal. Psico, 40(4), 430-437.

Scorsolini-Comin, F., \& Santos, M. A. (2010a). Psicologia positiva e os instrumentos de avaliação no contexto brasileiro. Psicologia: Reflexão e Crítica, 23(3), 411-419.

Scorsolini-Comin, F., \& Santos, M. A. (2010b). Satisfação com a vida e satisfação diádica: correlações entre construtos de bem-estar. PsicoUSF, 15(2), 249-256.

Scorsolini-Comin, F., \& Santos, M. A. (2011a). Ajustamento diádico e satisfação conjugal: correlações entre os domínios de duas escalas de avaliação da conjugalidade. Psicologia: Reflexão e Crítica, 24(2), 439-447.

Scorsolini-Comin, F., \& Santos, M. A. (2011b). Casamento e satisfação conjugal: um olhar da Psicologia Positiva. São Paulo: Annablume/FAPESP; Brasília: CNPq.

Seligman, M. E. P. (2004). Felicidade autêntica: usando a nova psicologia positiva para a realização permanente. Rio de Janeiro: Objetiva.

Seligman, M. E. P. (2011). Florescer: uma nova compreensão sobre a natureza da felicidade e do bem-estar. (C. P. Lopes, Trad.). Rio de Janeiro: Objetiva.

Siegel, S., \& Castellan, N. J. (1998). Nonparametric statistics for the behavioral sciences. Nova Iorque: McGraw-Hill College.

Snyder, C. R., \& Lopez, S. J. (2009). Psicologia positiva: uma abordagem cientifica e prática das qualidades humanas. (R. C. Costa, Trad). São Paulo: Artmed.

Spanier, G. B. (1976). Measuring dyadic adjustment: new scales for assessing quality of marriage and similar dyads. Journal of Marriage and the Family, 38(1), 15-28.

Stones, M. J., Worobetz, S., \& Brink, P. (2011). Overestimated relationships with subjective well-being. Canadian Psychology, 52(2), 93-100.

Watson, D., Clark, L. A., \& Tellegen, A. (1988). Development and validation of brief measures of positive and negative affect: the PANAS scales. Journal of Personality and Social Psychology, 54, 1063-1067.

Zou, K. H., Tuncali, K., \& Silverman, S. G. (2003). Correlation and simple linear regression. Radiology, 227, 617-628.

Fabio Scorsolini-Comin, doutor em Psicologia pela Faculdade de Filosofia, Ciências e Letras de Ribeirão Preto da Universidade de São Paulo, é professor adjunto da Universidade Federal do Triângulo Mineiro. Endereço para correspondência: Departamento de Psicologia, Universidade Federal do Triângulo Mineiro, Avenida Getúlio Guaritá, 159, Abadia, Uberaba-Minas Gerais, MG. CEP: 38025-440. Telefone: (34) 3318 5929. E-mail: scorsolini_usp@yahoo.com.br

Manoel Antônio dos Santos, doutor em Psicologia Clínica pelo Instituto de Psicologia da Universidade de São Paulo, é livre-docente em Psicoterapia Psicanalítica pela Faculdade de Filosofia, Ciências e Letras de Ribeirão Preto da Universidade de São Paulo, é professor associado do Departamento de Psicologia da Faculdade de Filosofia, Ciências e Letras de Ribeirão Preto da Universidade de São Paulo. E-mail: masantos@ffclrp.usp.br Roberto Molina de Souza, mestre em Saúde na Comunidade pela Faculdade de Medicina de Ribeirão Preto da Universidade de São Paulo, é professor de ensino superior na Universidade Tecnológica Federal do Paraná. E-mail: rmolinasouza@utfpr.edu.br 